\title{
Challenges of Teaching Roma Minority Children How to Read: What Do We Know and What Can We Do About It?
}

\author{
Raluca Pop
}

Faculty of Psychology and Educational Sciences, Babeș-Bolyai University, Romania

\section{ARTICLE INFO}

Keywords:

Academic achievement income

Reading comprehension

Roma children

Socioeconomic status

\begin{abstract}
The development of literacy skills of children from disadvantaged backgrounds has always been a relevant topic in education as it represents a means of reducing poverty and of improving living conditions. This paper focuses on the Roma minority, a historically disadvantaged minority and the largest ethnic group in Europe that has been reported to have a low literacy rate compared with their non-Roma counterparts. This study intends to identify the main challenges that Roma children face when they learn how to read and point out potential educational practices that can alleviate the condition of Roma children by helping them to improve their literacy development rate.
\end{abstract}

\section{Introduction}

Reading enhances the development of vocabulary, of decoding skills, of phonological awareness and of complex syntactic structures (Hulme et al., 2020; Frankel et al., 2016; Lervåg et al., 2019). It is a twofold process that entails word recognition (decoding) and language comprehension (Gough \& Tunmer, 1986). A considerable amount of language learning is delivered in school in written form and therefore reading skills become predictors of academic achievement. The effect of poverty on reading comprehension has been investigated in several studies (Dolean et al., 2019; Lervåg et al., 2019; Baucal, 2006). An ethnic minority that is struggling with severe poverty and social exclusion is the Roma community that is concentrated in Central and South-Eastern Europe (UNICEF, 2011). In Romania, $70 \%$ of Roma families have an income that is less than the official poverty threshold (Agency for Fundamental Rights [AFR], 2016). For Roma children living in severe poverty, learning to read poses some challenges that are mainly grounded in inadequate language experiences, parents' income and educational level, home environment (Hoff, 2006), access to educational resources (Bradley \& Corwyn, 2002), parenting behaviour and quality time spent with parents (Milne \& Plourde, 2006).

Roma children struggling with poverty are difficult to reach in research due to absenteeism (mobility, illness etc.) or social inequalities and therefore, few studies targeting the Roma community have been conducted in order to investigate the impact that severe poverty has on reading comprehension. One research conducted in Serbia indicates a large difference (1.2 standard deviation) in national testing in reading comprehension between Roma children and their non-Roma peers (Baucal, 2006). A comprehensive longitudinal research conducted in Romania, found that initial levels of reading comprehension between Roma and non-Roma children were as high as one standard deviation (Lervåg et al., 2019). Another longitudinal research concluded that Roma children enrolled in primary school, in Romania, had lower reading skills at the beginning of the study and slower development rates afterwards (Dolean

* Corresponding Author E-Mail Address: raluca.petrus@yahoo.com 
et al., 2019). These findings report that socio-economic status (SES) has explained a considerable amount of the variance in the initial status of Roma children's reading skills (Dolean et al., 2019) and the differences in growth (ranging from 8.6\% to 22.2\%) in reading comprehension between Roma and non-Roma children (Lervåg et al., 2019, p. 11). SES is a complex variable that is usually defined by several indicators including income level, education and occupational status. This paper intends to explain some of the contextual factors that have an impact on the reading comprehension of Roma children enrolled in schools. In addition, the paper indicates potential educational practices that can alleviate Roma children's condition by helping them to improve their literacy development rate.

\section{Challenges of Developing Roma Children's Reading Comprehension}

Reading comprehension is according to the simple view of reading (Gough \& Tunmer, 1986) mediated by phonological awareness and knowledge of vocabulary. Empirical research indicates that poverty has a negative impact on both Roma children's phonological awareness and vocabulary. Thus, on the one hand this leads to the fact that "the phonological awareness skills of Roma children are significantly lower than those of their non-Roma peers in $1 \mathrm{st}$ grade "(Dolean et al., 2016) and on the other hand, that poverty is associated with low levels of vocabulary (Biro et al., 2009). The significantly lower rates in phonological awareness and acquired vocabulary of Roma children have a negative impact on developing reading comprehension.

As indicated above, the challenges of teaching Roma children how to read are grounded in the lack of significant prerequisites (phonological awareness and vocabulary) when they start compulsory education. This is also connected to the fact that only $38 \%$ of Roma children enrol in pre-school education (AFR, 2016) which provides a starting point for pre-literacy skills. This gap in knowledge is already visible in primary education as Roma children "learn to read at a slower pace than their peers with higher SES" (Dolean et al., 2019). Slower growth rates in reading comprehension of Roma children emerge also because only about $20 \%$ of the Roma children ever complete primary school (UNICEF, 2011, p. 2).

Roma children have been reported to have increased absence rates in comparison to their non-Roma counterparts. Linked to this, empirical evidence indicates that school absence has an impact both on Roma children's decoding skills (Dolean et al., 2019; Dolean et al., 2016) and on their reading comprehension (Lervåg et al., 2019). Moreover, reading comprehension is also mediated by Roma children's bilingualism and performance in non-verbal ability tests (Dolean \& Calugar, 2020; Lervåg et al., 2019). Within this line of thought, several demographic factors and other mediators indicated below act, in varying degrees, as barriers to the development of Roma children's reading comprehension.

\subsection{Family Income}

Poverty produces harmful negative effects on the whole being ranging from lack of providing for basic daily needs, to scarce opportunities for exposure to formal education and quality academic resources, to promoting insecurity and stress, inappropriate living conditions or increased rates of illness. The lack of financial resources urges most of the Roma children living in poverty to have poor living conditions, to lack adequate nutrition and to have a struggling day-to-day life. In this respect, Jensen (2009) points out how chronic stress sustained over time in the case of disadvantaged children can have an impact on their physical, psychological, emotional, cognitive functioning, social competence and academic progress. Empirical evidence has indicated that poverty is associated with low levels in literacy skills (Sirin, 2005; Owens, 2018; Buckingham et al., 2013) and that family SES acts as a salient role in children's reading skills (Hoff, 2006; Dolean et al., 2019; Lervåg et al., 2019). Moreover, childhood poverty has implications for school readiness as it creates 
achievement gaps that widen over time (Hoff, 2013) and generate disparities in educational attainment (Ryan, Fauth \& Brooks-Gunn, 2006). Roma children have a significant disadvantage when they start school and SES factors have a direct influence on their initial reading comprehension (Lervåg et al., 2019).

Low income and poverty produce effects in language learning even before children's enrolment in compulsory education. Thus, differences in oral language skills of children of low SES are already evident by the age of 18 months (Fernald, Marchman \& Weisleder, 2013). A consequence of poverty is the fact that "the home language environment of children from lower SES backgrounds is typically less language rich than that of children from higher SES backgrounds (Hulme et al., 2020, p. 2). These lower levels in verbal skills (decoding and phonological awareness) and vocabulary exhibited by children living in poverty will have, according to the 'simple view of reading, a negative impact on reading comprehension. Lack of exposure to meaningful language input will hinder disadvantaged children from engaging in relevant contexts in order to make use of diverse vocabulary items, of phonological awareness and of decoding skills.

Roma families with severe low income may not be able to offer their children an appropriate home environment that supports learning (e.g., a study area and the necessary study materials). The major setback for developing reading skills as a consequence of SES factors present in the home environment of poverty-stricken children could be at least theoretically compensated for in the context of formal education. Unfortunately, research findings indicate that Roma children in Romania continue to lag behind their non-Roma peers even after they attend formal education because "schools are not able to compensate for differences in SES when it comes to improving reading" (Dolean et al., 2019, p. 8).

A constant increased income would provide parents with the means to invest in one's child enrichment through various educational tools, extracurricular activities or high quality childcare (Owens, 2018) and it would also leave room for non-financial resources such as time allotted to reading and to constructive interactions with the child (Volante et al., 2019). In addition, increased income would allow parents to make some changes in terms of choosing the environment the child is faced with at home (overcrowded dwellings) or in the neighbourhood (dangerous environment). Because income is a decisive factor of where one lives (Belinger, 2017) consistent evidence indicates that a disadvantaged neighbourhood reduces both cognitive skills and verbal skills (Owens, 2018). By living in crowded Roma settlements that lack basic amenities as $68 \%$ live in Romania in households without running water (AFR, 2016) parents cannot provide for an "adequate educational climate within their families" (Biro et al., 2009, p. 273).

Poverty and low family income have an impact also on school enrolment. A needs assessment study for Roma population in South-Eastern Europe concluded that gaps in enrolment are the greatest in Albania, Bosnia and Herzegovina and Montenegro where these rise to about $45 \%$ to $50 \%$ while $20 \%$ of Roma children in Bulgaria and 33\% in Serbia never go to school (UNICEF, 2011). Thus, according to UNICEF (2011, p. 18) the lack of learners' school readiness in terms of language level and non-verbal abilities has a negative impact on children's capacity to benefit from primary education. As concerns the access of children to education, a Presidential Report issued in Romania in $2007^{1}$ indicates that there is inequity as regards children's access to education. Thus, the Presidential report concludes that approximately $80 \%$ of the children who have never enrolled in schools are Roma and that almost $38 \%$ of them are functional illiterates. In addition, taking as a reference point 2005,

\footnotetext{
${ }^{1}$ Romanian Presidency, Romania of Education, Romania of Research. The Presidential Committee Report for the analysis and elaboration of politics in education and research, Bucharest, July 2007, http://old.presidency.ro/static/rapoarte/Raport_CPAEPDEC.pdf
} 
only $64 \%$ of the Roma children were enrolled in primary education, as compared to $98.9 \%$, the national average (Presidential Report, 2007, p. 8). Although the social and educational inclusion of the Roma minority have been a priority in the past 20 years both in Romania and in the European Union, a scarce amount of empirical research has been conducted in order to identify the factors that influence the development of Roma children's reading skills, to increase enrolment rates and to diminish school dropout.

\subsection{Parents' Education}

Parents and caretakers' language practices have a salient role in fostering young children's language development. As such, their language practices become a model and a relevant language input for their children. In the case of Roma communities, parents are often illiterate and thus, it is difficult for them to provide a consistent support to their children once enrolled in compulsory education (Biro et al., 2009).

Several studies have brough evidence that parental education is the best predictor of academic achievement (Sammons et al., 2004), concluding that mother's education plays an important role in supporting early literacy development (McEwan, 2003; Fantuzzo et al., 2014; Dolean et al., 2016). A pilot survey conducted on 438 Roma respondents living in nine EU Member States provided an overview of respondents' parental education level. Thus, the findings indicate that only $23 \%$ of Roma fathers and almost $19 \%$ of Roma mothers continued education after primary level was completed (Pita et al., 2016, p. 38). Moreover, 107 of Roma fathers and 136 of Roma mothers did not receive any type of academic education (Pita et al., 2016, p. 39). These findings situate Roma parents within a low education level which implicitly has consequences on their reading comprehension and language proficiency. Moreover, lack of parental education has a detrimental effect of children's literacy development because children do not receive appropriate exposure to language and thus their linguistic opportunities are narrowed.

A recent report on Roma population in Romania indicates that "the level of illiteracy is $10 \%$ higher among women compared to men" (European Commission, 2018, p. 28). This percentage is particularly worrisome as mother's education represents an important determinant of children's reading comprehension mediated through phonological awareness and the amount of vocabulary exposure the child receives at home. Empirical research indicates a significant medium correlation between Roma children's phonemic awareness and the mother's education level in the context of enhancing pre-literacy skills (Dolean et al., 2016). This finding needs to be linked to the type of vocabulary that is used in low-SES families. Investigations on this topic conclude that the style of interaction tends to be different in low SES families as opposed to high SES families. Thus, the parent-child interaction in low-income families involves more directives and not so many complex sentence structures and diversified vocabulary in comparison to higher-SES families where much more focus is placed on engaging in conversation (Hulme et al., 2020). Children's verbal skills are thus influenced by environmental input. In an effort to reframe this argument, other findings come to support that variation in the syntactic complexity of maternal speech can substantially explain SES-related differences in the syntactic complexity of 5-year-old children's speech (Huttenlocher et al., 2002). Further research indicates that in SES families, parents' educational level positively correlates with the frequency of parentchild literacy activities (Li et al., 2020). Thus, parents' literacy abilities influence the parentchild interactions and in their turn, provide a basis for developing vocabulary and reading skills.

Motivation represents a salient variable in academic achievement because without sufficient motivation one cannot attain long-term goals (Dörnyei, 1998). If children do not have enough motivation to keep studying, then parents should provide the necessary encouragement and 
motivation. However, Roma children represent a population at high risk for educational failure because of their parents' views on the relevance or necessity for attending compulsory education. In this line of thought, Dolean et al., (2016, p. 47) indicate that "Roma families might not place a great value on their educational level because their income does not depend on it". In addition, "school institution has no tradition in Roma family" (Tourtouras et al., 2016, p. 12). Such a perspective on education is consistent with the low enrolments rates in the number of Roma children.

Having as a starting point the Education and Employment Situation of Roma in 8 EU Member States data (Pita et al., 2016), it could be concluded that Roma parents are often illiterate and attain a low level of education which as a result, has an impact on their understanding of the role played by formal education. Parents who are not educated face the risks of not being able to tutor their children and help them achieve the necessary reading skills.

\subsection{Parental Occupation}

Occupational status is to a certain degree connected to income and to one's educational attainment. A low occupational status generally implies a low wage as a consequence of the unskilled labour that is performed. In the particular case of employed Roma parents, most of them belong to three groups: temporary workers, unskilled workers and self-employed (Cace et al., 2007). A report conducted in the Republic of Moldova indicates that $40 \%$ of adult members in poor Roma households are unemployed, 5\% are employed and self-employed and another $18 \%$ perform occasional work (Cace et al., 2007). In this respect, occupational status determines the family's income level which acts as an important variable in the development of reading comprehension. Roma families' occupational status is influenced by their level of education, but high unemployment rates can be also the outcome of segregation, racism and discrimination (AFR, 2014). One aspect to consider is that the level of job insecurity tends to be higher in the case of low occupational status because not so many working opportunities arise when one has achieved an insufficient level of education. Therefore, parents who perform these types of jobs are constantly fearful about the family's income level and invest extra time at work which otherwise would have been valuable time spent with the family. In addition, such insecurity leaves little room for engagement and involvement with children in the family. Research conducted in this area indicates that parents' involvement in children's education is positively related to children's achievement in school (Hill et al., 2004) through the motivation and support provided in order to overcome difficulties linked to learning.

On a general note, as indicated above, a considerable amount of literature has concluded that living in extreme poverty influences considerably academic achievement. SES factors (family's income, parent's education and their occupational status) summarized above can have an impact on developing children's reading skills, phonological awareness and amount of acquired vocabulary. Below are indicated some other factors that can impede the development of reading skills.

\subsection{Parenting Practices and The Parent-Child Relationship}

Roma minority is a group that has "different cultural and financial family backgrounds" (Tourtouras et al., 2016, p. 18). Having this as a starting point, it might be so that Roma minority has contrastive priorities and perspectives upon life, education and parenting practices. One particular case is that of young Roma girls who face cultural and social pressures and are not allowed to continue their academic studies after a certain age (UNICEF, 2011, p. 19). As an embedded cultural practice, Roma girls often marry before the legal age of marriage and this, coupled with a pregnancy, hinder the access of Roma girls to formal education and thus to achieving reading skills. 
Even if almost $80 \%$ of the Roma parents state that they would like their children to complete at least secondary education level, the reality is that more than $75 \%$ of their children do not go on to secondary education (The World Bank, 2012). Thus, inconsistent parenting practices are maximizing the gap of functional literacy between Roma and non-Roma children. Roma parents' limited understanding of the learning environment and school expectations result in lack of support provided to Roma children. By not having higher prestige occupations as a consequence of their low level of education, Roma parents may not be able to guide their children's learning or serve as role models for their children's occupational aspirations (Hill et al., 2004).

A meta-analysis meant to investigate the influence of parental involvement on children's educational outcomes indicates that a positive parent-child relationship is correlated with good reading skills (Jeynes, 2007). Such a positive correlation has been observed in SES families where children's reading performance was influenced indirectly by the parent-child relationship established though parents' speech and behaviours (Chen et al., 2018). Meaningful speech acts provide a valuable linguistic input for young children and widen their vocabulary and phonological awareness. Parent-child relationships should be directed towards enhancing academic support outside the school and motivating the child to study and develop literacy. But as indicated above, Roma parents don't always have sufficient educational experience and they might lack the ability to provide tutoring and the necessary motivation to help their children in achieving literacy (Biro et al., 2009, p. 274). Considering the well acknowledged effect of SES on children's reading ability, empirical findings conclude that initiative factors, such as motivation to study, can moderate the effect of SES on reading skills and academic achievement (Chen et al., 2018). Thus, individual characteristics such as a strong motivation to study can strengthen the ability of children to cope with the disadvantages of low SES (Chen et al., 2018).

\subsection{Bilingualism}

A potential mediator between SES and reading comprehension is bilingualism. Linguistic barriers might arise in the case of children living in poverty as they use a different language at school in comparison to the language spoken at home. According to Hoff (2013), being part of a minority and having a different mother tongue can account for different developmental trajectories because in language minority homes children are equipped with lower levels of the official language in comparison to monolingual students. Therefore, considering the case of Roma children, they face huge challenges in school because the language of instruction is not always their first language. When engaging in reading activities, this can place them at a significant disadvantage in comparison with other nonRoma children because they have gaps in vocabulary and in decoding skills. Because reading is a process that connects the known with the new (Frankel et al., 2016, p. 8), Roma children need to make meaning by connecting information found in print with their previous knowledge (knowledge about language discourse, understanding of social-cultural references, making own predictions and have expectations while reading). Thus, reading in a language that is not one's mother tongue might pose some challenges that address issues of identity, of perception and of sociocultural understanding.

Various studies indicate that bilingual children coming from low SES families exhibit poorer vocabulary and reading skills in their second language compared to monolingual children (Melby-Lervåg \& Lervåg, 2014; Hoff, 2006). Two particular studies focusing on Roma children have considered the variable of bilingualism and included in their research Roma children who were bilingual and monolingual. Findings indicate that both bilingual and monolingual Roma children possessed lower levels of vocabulary and reading comprehension in comparison to children that did not belong to this minority and that "bilingual Roma 
children possessed even lower levels than the monolingual children" (Lervåg et al., 2019). In addition, bilingual and monolingual Roma children exhibited "poorer reading skills at the beginning of the study and a slower subsequent development of their reading skills" (Dolean et al., 2019) compared to their non-Roma counterparts. A slower growth rate in reading comprehension skills can be explained by Roma children's low initial vocabulary (Lervåg et al., 2019) which can be linked to mother's education level, family's income level or the parent-child relationship. Lack of educational resources written in students' mother tongue coupled with lack of teachers who are able to speak learners' mother tongue represent elements that can have an impact on Roma children's subsequent development of reading skills.

\subsection{School Absence, Enrolment and Dropout}

When analysing the impact of SES on early reading development it is advisable to take into account learners' school absence. In this context, absence is relevant because "when children receive less instruction than their peers, they stand the risk of falling behind" (Lervåg et al., 2019) and attain gaps in knowledge. Various studies indicate that children struggling with poverty are absent from school more often than high SES learners (Lervåg et al., 2019; Ready, 2010; Kiprianos et al., 2012). In the case of Roma minority from Romania, absenteeism has high rates (Dolean et al., 2019; AFR, 2016) and is caused by out-of-school factors (duties at home, living conditions, illnesses, parents' views on the usefulness of education, access to school) and by in-school-factors (discrimination, segregation, underprepared teachers, inappropriate teaching resources, lack of education in their mother tongue). Building on previous knowledge according to which children who live in poverty enter school with less vocabulary knowledge than children with higher SES (Farkas \& Beron, 2004; Hoff, 2006) and that Roma children learn to read at a slower rate compared to their non-Roma peers (Dolean et al., 2019) findings indicate that school absence does influence the development of reading comprehension and that absence can be predicted by children's SES (Lervåg et al., 2019). In what concerns Roma children's enrolment in elementary school, their poor school attendance had a negative effect on the development of their reading fluency and thus they "are particularly vulnerable when they are not present in class" (Dolean et al., 2016, p. 10).

In addition to school absence, of relevance for Roma children's reading and vocabulary development is their attendance at compulsory education at a level corresponding to their age. Because of their school absence coupled with SES, Roma children lag behind their non-Roma peers and $18 \%$ of them attend compulsory school at an educational level that is lower than the one corresponding to their age (AFR, 2016). Some causes for this could reside in the fact that Roma children repeat classes as they have gaps in knowledge or might start school later as SES factors, discrimination and lack of learning motivation are conducive to poor enrolments rates for Roma children. Gaps in knowledge might be the result of teachers' level of pedagogical content knowledge as "it is not uncommon for the weakest students in academic subjects to be assigned teachers that are low in quality" (Berliner, 2017, p. 24).

Enrolment constitutes a major issue of concern for Roma children in Eastern Europe as 50\% of the Roma between 6 and 24 years of age do not attend school (AFR, 2016, p. 26) thus supporting the transmission of poverty. Pre-school education is of high importance because it enables Roma children to develop appropriate learning skills and it stops "perpetuating preexisting achievement gaps" (Entwisle et al., 2003). Still, only 37\% of Roma children aged 3 to 6 years old benefit from pre-school education as compared to $77 \%$ enrolment for nonRoma children (European Commission, 2018, p. 32). Dropout can occur as a result of transitioning toward a lower educational level, because of bullying and discrimination or other forms of vulnerability connected to children's ethnicity. Empirical research indicates 
that poor literacy skills can also be at fault for the dropout rate of Roma children (Baucal, 2006; Kiprianos et al., 2012).

Following this line of thought, participation of Roma children in regularly school activities can enhance their literacy attainment. Therefore, a strong emphasis needs to be placed on adequate social and school integration of Roma children to ensure school performance (Dolean et al., 2016).

\subsection{Segregation}

The 2013 Council Recommendation requested the elimination of school segregation by promoting equal participation of all Roma children in schools (AFR, 2016). Even so, various forms of segregation are still present: social marginalization, living conditions, overrepresentation is classes or access to qualified teachers. Segregation based on ethnicity and social status increases the degree of inequality in educational contexts and impedes SES children to benefit from the advantages of a diverse multi-level classroom. Research in this field concludes that children with low SES have better scores in reading and mathematics when they are not being taught to in classes with large concentrations of other classmates with low SES (Berliner, 2017). Likewise, low SES students receive valuable exposure to different types of input which is beneficial for their learning outcomes. Connected to this, low ability students are increasing their school achievement if they have in their classes more knowledgeable students (Levin, 2001).

The ethnic composition of school classes attended by Roma children in different countries within the European Union indicates different scores that delineate three main groups: Roma children attending schools or classes where all or many of their classmates are also Roma; Roma children attending ethnically mixed classes; and classes where there are few or no Roma classmates (AFR, 2016). The educational segregation of Roma students has a salient impact on their career aspirations and it diminishes their opportunities to engage in continuing education (AFR, 2016). The Ministry of Education from Romania adopted in 2007 a low prohibiting school segregation and even this topic is thoroughly debated in the public space, no official data are available on this subject.

\subsection{Non-Verbal Abilities}

Various studies suggest that economically disadvantaged children tend to exhibit a significant amount of variance in their performance in non-verbal abilities tasks in comparison to children who come from a high SES environment (Heckman, 2006; Hanscombe et al., 2012). Contextual factors that correlate with such performance refer to insufficient cognitive stimulation provided at home, parents' low levels of literacy and poverty (Guo \& Harris, 2000). Few empirical studies have measured the non-verbal abilities of the Roma minority. In Serbia, Rushton et al. (2007) conducted a research on Roma adults and measured their performance in IQ tests by using Raven's Progressive Matrices. The results concluded that Roma respondents had a poor performance in non-verbal abilities in comparison to the nonRoma population. This particular research assessed only cognitive abilities and did not take into consideration additional variables, such as SES, that might explain the poor performance scores of Roma respondents. Rushton et al. (2007) indicated that one limitation of their study resides in the fact that the scores of Roma respondents might be linked to their lack of educational background. This aspect is relevant as education represents a means of raising one's intelligence (Ritchie \& Tucker-Drob, 2018). As already reported in this paper, few Roma learners continue their secondary or upper secondary education and even fewer enrol in tertiary level. Thus, lack of education has a negative impact on both reading comprehension and cognitive development. Therefore, the results of Roma's performance on IQ tests might be a consequence of their low educational level (Dolean \& Calugar, 2020). 
Two other studies provide different views on assessing Roma children's non-verbal abilities. The first one concludes that variance in non-verbal abilities is attributed to different cognitive variables such as general intelligence, phonological awareness and working memory (Dolean \& Tincas, 2018). The second study considered the effects of SES on the IQ test performance of Roma children. The results indicate a strong effect of Roma parents' education and living conditions on children's IQ tests and that the effect size between the means of the two groups (Roma and non-Roma) was medium, "with ethnicity explaining $18 \%$ of the variance of the IQ test performance" (Dolean \& Calugar, 2020, p. 5). These results are partially explained by the fact that Roma parents cannot fully provide proper academic support and cognitive stimulation for their children because they are themselves early leavers from education. In addition, poor living conditions and overcrowded homes can be detrimental to children's cognitive development (Solari \& Mare, 2012) and phonological awareness (Dolean et al., 2016) as these do not cater for a supporting learning environment. A low performance in IQ tests can also be attributed to participants' food intake (Von Stumm, 2012) as lack of access to proper nutrition impedes cognitive development. But Roma children are struggling with poverty and thus, they might lack the necessary nutrients when they attend school or when they perform non-verbal ability tests. This aspect needs to be taken into consideration when conducting research. Another key element to look at is the relationship between absenteeism and cognitive development. Empirical research indicates that Roma children exhibit higher rates of absenteeism in comparison to their non-Roma peers (Dolean et al., 2019) and likewise, this causes gaps in knowledge that widen over time. When exploring the challenges of teaching Roma minority children how to read one needs to consider school absence as a mediator between Roma children's cognitive development and their reading comprehension.

\subsection{Discussion About Potential Educational Practices That Can Improve Roma Children's Reading Comprehension Rate}

This paper concluded that there are a variety of challenges that Roma children face when they learn how to read. Most of these challenges are accounted for by SES and other contextual factors (school absence, parent-child relationship or bilingualism). Thus, when considering potential educational practices that could improve Roma children's reading comprehension it is necessary to establish realistic aims and consider the impact of both out-of-school factors (poor living conditions, illness, parents' views on the usefulness of education, learners' motivation) and of in-school-factors (discrimination, segregation, underprepared teachers, inappropriate teaching resources, lack of education in their mother tongue) on increasing reading comprehension.

First of all, out-of-school factors are more difficult to control or to alleviate. In the case of Roma children's poor living conditions, a combination of macro-level (e.g. implementation of policies) and micro-level (e.g. individual needs) measures need to be considered. As indicated in the paper, poverty exerts a negative impact on both Roma children's phonological awareness and vocabulary as a consequence of insufficient cognitive stimulation at home. In addition, Roma children start school already with a gap in knowledge which widens due to school absence (Dolean et al., 2019) and lack of personal motivation. Therefore, parenting programmes for Roma parents could be a feasible option in order to address the need of placing reading in a new perspective. These should be targeted towards developing an efficient family-school collaboration so that the effort to enhance reading in the formal educational environment is understood, supported and continued at home. Roma children should be encouraged to become responsible autonomous learners who find the necessary motivation to continue studying outside the classroom. Because many Roma parents have a low level of education or might struggle with illiteracy, they might not understand the usefulness of reading, of encouraging children to read and of providing a 
supportive environment that is conducive to learning. Therefore, Roma parents should take part in programmes and school meetings directed towards making them more aware of the opportunities offered by education and in particular, by reading comprehension.

Secondly, in-school-factors are easier to control because there are rules and regulations that need to be followed. The school environment should support Roma children's reading comprehension by using diverse teaching resources and methods focused on individual learning. Differentiated instruction is needed because when Roma children enrol in compulsory education, they already have a significant disadvantage grounded in the fact that only a small part of them access pre-primary education and that their parents, lacking themselves education, cannot provide much support at home. Another issue to consider within the school system is that teachers who teach to Roma children might have insufficient qualification to design differentiated instruction, to be able to teach to a mixed-ability group and might not have a complex understanding of the multilingual and the multicultural environment within the classroom. As already stated, making meaning out of reading implies connecting what is already known to what is new. But Roma children, as a consequence of absenteeism, bilingualism and poor initial levels of reading comprehension (Lervåg et al., 2019) start school with a disadvantage that needs to be tackled.

Taken together, these perspectives address the need to conduct more studies on children living in poverty in order to examine "how the nature of cognitive stimulation at home, nutrition and mother/child health services received during pregnancy and early childhood affect children's development" (Lervåg et al., 2019, p. 12) and their reading comprehension. It is also necessary to conduct intervention studies, from an early age, that would focus on building Roma children's language comprehension and vocabulary (Lervåg et al., 2019) as prerequisites for developing reading comprehension.

\section{Conclusion}

This study has identified in the literature some of the effects that social economic status, coupled with other contextual factors, have on Roma children's reading comprehension and on its components - phonological awareness, vocabulary acquisition and decoding skills. Family's income, parents' education and their occupational status, bilingualism, school absence, the parent-child relationship and non-verbal abilities mediate, in varying degrees, the development of Roma children's reading comprehension. With regard to improving Roma children's reading comprehension scores, there is immediate need to conduct further research and more intervention studies in order to support the literacy development of this minority and reduce their level of poverty.

\section{Acknowledgment}

This work was supported by EEA Grants 2019-2023, project EEA-RO-NO-2018-0026, grant number $10 / 2019$.

\section{References}

Agency for Fundamental Rights, (2016). Second European Union Minorities and Discrimination Survey. Roma- Selected Findings. Available: https://fra.europa.eu/en/ publication/2016 /fundamental-rights-report-2016

Baucal, A. D. (2006). Development of mathematical language literacy among Roma students. Psihologija, 39(2), 207-227. doi:10.2298/PSI0602207B

Berliner, D. C. (2017). Poverty's powerful effects on reading achievement and the achievement gap. In R. Horowitz and S. J. Samuels (Eds.). The achievement gap in 
reading: Complex Causes, persistent issues, possible solutions (pp. 23-37). Oxon, New York: Routledge, Taylor \& Francis

Biro, M., Smederevac, S. and Tovilovic, S. (2009). Socioeconomic and cultural factors of low scholastic achievement of Roma Children, p. 273-288. Psihologija, vol 42 (3). doi:10.2298/PSI0903273B

Bradley, R. H. and Corwyn, R.F. (2002). Socioeconomic status and child development. Annual Review of Psychology, 53, pp. 371-400.

Buckingham, J., Wheldall, K., and Beaman-Wheldall, R. (2013). Why poor children are more likely to become poor readers: The school years. Australian Journal of Education, 57(3), 190-213. doi:10.1177/0004944113495500

Cace, S., Cantarji, V., Sali, N. and Alla, M. (2007). Roma in the Republic of Moldova. The United Nations Development Programme Moldova: Chisinau. Available: https://www.researchgate.net/publication/293487948_Roma_in_the_Republic_of_Moldo va

Chen, Q., Kong, Y., Gao, W. and Mo, L. (2018). Effects of Socioeconomic Status, ParentChild Relationship, and Learning Motivation on Reading Ability. Frontiers in Psychology, 9: 1297. doi: 10.3389/fpsyg.2018.01297

Dolean, D. and Calugar, A. (2020). How Reliably Can We Measure a Child's True IQ? Socio-Economic Status Can Explain Most of the Inter-Ethnic Differences in General Non-verbal Abilities. Frontiers in Psychology, volume 11. doi:10.3389/fpsyg.2020.02000

Dolean, D.D., Melby-Lervåg, M., Tincas, I., Damsa, C. and Lervåg, A. (2019). Achievement gap: socioeconomic status affects reading development beyond language and cognition in children facing poverty. Learning and Instruction, 63(2019), 1-10. doi: 10.1016/j.learninstruc.2019.101218

Dolean, D. D., and Tincas, I. (2018). Cognitive factors explain inter-cultural variations of abilities in rhythm perception: the case of Roma minority. Psychology of Music, 8:715. doi: $10.1177 / 0305735618766715$

Dolean, D., Tincaș, I. and Damșa, C. I. (2016). Enhancing the Pre-literacy Skills of Roma Children: The Role of Socio-economic Status and Classroom Interventions in the Development of Phonemic Awareness. The New Educational Review, 39-51. doi: 10.15804/tner.2016.45.3.03

Dörnyei, Z. (1998). Motivation in second and foreign language learning. Language Teaching, 31, 117-135. doi:10.1017/S026144480001315X

Gough, P. B. and Tunmer, W. E. (1986). Decoding, reading and reading disability. Remedial and Special Education, 7(1), pp. 6-10. doi: 10.1177/074193258600700104

Entwisle, D. R., Alexander, K. L., and Olson, L. S. (2003). The first-grade transition in life course perspective. In J. T. Mortimer \& M. J. Shanahan (Eds.), Handbook of the life course. New York: Kluwer Academic/Plenum. doi:10.1007/978-0-306-48247-2_11

European Commission (2018). Civil Society Monitoring Report on Implementation of the National Roma Integration Strategy in Romania Focusing on structural and horizontal preconditions for successful implementation of the strategy. Available: https://cps.ceu.edu/sites/cps.ceu.edu/files/attachment/basicpage/3034/rcm-civil-societymonitoing-report-1-romania-2018.pdf 
Fantuzzo, J. W., LeBoeuf, W. A. and Rouse, H. L. (2014). An investigation of the relations between school concentrations of student risk factors \& student educational well-being. Educational Researcher, 43(1), 25-36. doi: 10.3102/0013189X13512673

Farkas, G., and Beron, K. (2004). The detailed age trajectory of oral vocabulary knowledge: Differences by class and race. Social Science Research, 33, 464-497. doi: 10.1016/j.ssresearch.2003.08.001

Fernald, A., Marchman, V.A. and Weisleder, A. (2013). SES differences in language processing skill and vocabulary are evident at 18 months. Developmental Science 16:2 (2013), pp 234-248. doi: 10.1111/desc.12019

Frankel, K. K., Becker, B. L. C., Rowe, M. W. and Pearson, P. D. (2016). From "What is Reading?" to What is Literacy?. Journal of Education, volume 196 (3), 7-17. doi:10.1177/002205741619600303.

Guo, G., and Harris, K.M. The mechanisms mediating the effects of poverty on children's intellectual development. Demography 37, 431-447 (2000). doi:10.1353/dem.2000.0005

Hanscombe, K. B., Trzaskowski, M., Haworth, C. M. A., Davis, O. S. P., Dale, P. S., and Plomin, R. (2012). Socioeconomic Status (SES) and Children's intelligence (IQ): in a UK-representative sample SES moderates the environmental, not genetic, effect on IQ. PLoS One 7:e30320. doi: 10.1371/journal.pone.0030320

Heckman, J. J. (2006). Skill formation and the economics of investing in disadvantaged children. Science 312, 1900-1902. doi: 10.1126/science.1128898

Hill, N. E., Castellino, D. R., Lansford, J. E., Nowlin, P., Dodge, K. A., Bates, J. E. and Pettit, G. S. (2004). Parent academic involvement as related to school behaviour, achievement, and aspirations: demographic variations across adolescence. Child Development, 75, 1491-1509. doi: 10.1111/j.1467-8624.2004.00753.x

Hoff, E. (2013). Interpreting the Early Language Trajectories of Children From Low-SES and Language Minority Homes: Implications for Closing Achievement Gaps. Developmental Psychology 49(1). doi: 10.1037/a0027238

Hoff, E. (2006). How social contexts support and shape language development. Developmental Review, 26(1), 55- 88. doi:10.1016/j.dr.2005.11.002

Hulme, C., Snowling, M., West, G., Lervåg, A. and Melby-Lervåg, M. (2020). Children's Language Skills Can Be Improved: Lessons from Psychological Science for Educational Policy. Current Directions in Psychological Science. doi: 10.1177/0963721420923684

Huttenlocher J., Vasilyeva M., Cymerman, E. and Levine, S. (2002). Language input and child syntax. Cognitive Psychology, 45, 337-374. doi: 10.1016/S0010-0285(02)00500-5

Jensen, E. (2009). Teaching with Poverty in Mind: What Being Poor Does to Kids' Brains and What Schools Can Do About It. ASCD

Jeynes, W. H. (2007). The Relationship Between Parental Involvement and Urban Secondary School Student Academic Achievement: A Meta-Analysis. Urban Education, 42(1), 82110. doi:10.1177/0042085906293818

Kiprianos, P., Daskalaki, I. and Stamelos, G.B. (2012). Culture and the school: The degree of educational integration of Roma and Gypsies in the Peloponese region of Greece. International Review of Education, 58 (5), 675-699. doi: 10.1007/s11159-012-9326-0

Lervåg, A., Dolean, D., Tincas, I. and Melby-Lervåg, M. (2019). Socioeconomic background, nonverbal IQ and school absence affects the development of vocabulary and reading 
comprehension in children living in severe poverty. Developmental Science, 22(5), Article e12858. doi:10.1111/desc. 12858

Levin, J. (2001). For whom the reductions count? A quantile regression of class size and peer effects on scholastic achievement. Empirical Economics, 26, 221-246 (2001). doi: $10.1007 / \mathrm{s} 001810000054$

Li, S., Nan, N., Xu, Q., and Li, J. (2020). Perceived quality of parent-child relationships by Chinese primary school students: The role of parents' education and parent-child literacy activities. Child Language Teaching and Therapy, 36(2), 79-89. doi: 10.1177/0265659020915943

McEwan, P. (2003). Peer effects on student achievement. Evidence from Chile. Economics of Education Review, volume 22, issue 2, 131-141. doi: 10.1016/S0272-7757(02)00005-5

Melby-Lervåg, M. and Lervåg, A. (2014). Reading comprehension and its underlying components in second-language learners: A meta-analysis of studies comparing first and second-language learners. Psychological Bulletin, 140(2), 409. doi:10.1037 /a0033890

Milne, A. and Plourde, L.A. (2006). Factors of a Low-SES Household: What Aids Academic Achievement? Journal of Instructional Psychology, vol. 33, nr. 3, pp. 183-193

Owens, A. (2018). Income segregation between school districts and inequality in students' achievement. Sociology of Education, 91(1), 1-27, doi:10.1177/0038040 717741180

Pita, E., Konstantinou, K. and Anatoliki S.A. (2016). Education and Employment: The Situation of Roma in 8 EU Member States. Developmental Agency of Eastern Thessaloniki's Local Authorities Anatoliki S.A. Available: http://projectpal.eu/wpcontent/uploads/2016/10/PAL_WS1.4._analysis_ROMA_CURRENT_SITUATION_AN ATOLIKI_9.2016.pdf

Ready, D. (2010). Sociolinguistic disadvantage, school attendance and early cognitive development: The differential effects of school exposure. Sociology of Education, 83(4), 271-286. doi:10.1177/0038040710383520

Ritchie, S. J., and Tucker-Drob, E. M. (2018). How much does education improve intelligence? A meta-analysis. Psychol. Sci. 29, 1358-1369. doi: $10.1177 / 0956797618774253$

Romanian Presidency (2007). Romania of Education, Romania of Research. The Presidential Committee Report for the analysis and elaboration of politics in education and research, Bucharest, July 2007. Available: http://old.presidency.ro/static/rapoarte/Raport_ CPAEPDEC.pdf

Rushton, J.P. Cvorovic, J. and Bons, T.A. (2007) General mental ability in South Asians: Data from three Roma (Gypsy) communities in Serbia. Intelligence, 35(1), 1-12. doi: 10.1016/j.intell.2006.09.002

Ryan, R. M., Fauth, R. C., and Brooks-Gunn, J. (2006). Childhood poverty: Implications for school readiness and early childhood education. In B. Spodek \& O.N. Saracho (Eds) The handbook of research on the education of young children (pp. 323-346). New York: Routledge

Sammons, P., Elliot, K., Sylva, K., Melhuish, E. C., Siraj-Blatchford, I., and Taggart, B. (2004). The impact of pre-school on young children's cognitive attainments at entry to reception. British Educational Research Journal, 30:5, 691-712, doi: 10.1080/0141192042000234656 
Sirin, S. R. (2005). Socioeconomic Status and Academic Achievement: A Meta-Analytic Review of Research. Review of Educational Research, Sage Journals, volume: 75 issue: 3, 417-453. doi:10.3102/00346543075003417

Solari, R. D., and Mare, C. D. (2012). Housing crowding effects on children's wellbeing. Social Science Research, 41, 464-476. doi: 10.1016/j.ssresearch.2011.09.012

The World Bank. (2012). Toward an equal start: closing the early learning gap for Roma children in Eastern Europe. Washington, D.C.: World Bank Group. Available: http://documents.worldbank.org/curated/en/843991468251107542/Toward-an-equal-startclosing-the-early-learning-gap-for-Roma-children-in-Eastern-Europe

Tourtouras, C., Pavlis Korre M., and Kyridis, A. (2016). The School Career and the Educational Exclusion of the Roma Children in Greece. Journal of Sociological Research, vol. 7, no. 1, 10-32. doi: doi:10.5296/jsr.v7i1.8964

UNICEF (2011). The Right of Roma Children to Education. Position Paper. Available: https://www.unicef.org/eca/sites/unicef.org.eca/files/2017-11/Roma_Position_Paper__June12.pdf

Volante, L., Schnepf, S.V., Jerrim, J., and Klinger, D. A. (eds.) (2019). Socioeconomic inequality and student outcomes: cross-national trends, policies and practices. Springer Nature Singapore Pte Ltd.

Von Stumm, S. (2012). You are what you eat? Meal type, socio-economic status and cognitive ability in childhood. Intelligence 40, 576-583. doi: 10.1016/j.intell.2012.08.004 